\title{
Protection of live bacteria from bile acid toxicity using bile acid adsorbing resins
}

\section{Article}

Accepted Version

Manuscript

Edwards, A. D. and Slater, N. K.H. (2009) Protection of live bacteria from bile acid toxicity using bile acid adsorbing resins. Vaccine, 27 (29). pp. 3897-3903. ISSN 0264-410X doi: https://doi.org/10.1016/j.vaccine.2009.04.006 Available at https://centaur.reading.ac.uk/8003/

It is advisable to refer to the publisher's version if you intend to cite from the work. See Guidance on citing.

Published version at: http://dx.doi.org/10.1016/j.vaccine.2009.04.006

To link to this article DOI: http://dx.doi.org/10.1016/j.vaccine.2009.04.006

Publisher: Elsevier

All outputs in CentAUR are protected by Intellectual Property Rights law, including copyright law. Copyright and IPR is retained by the creators or other copyright holders. Terms and conditions for use of this material are defined in the End User Agreement.

\section{www.reading.ac.uk/centaur}

\section{CentAUR}

Central Archive at the University of Reading

Reading's research outputs online 


\title{
Protection of live bacteria from bile acid toxicity using bile acid adsorbing resins
}

Alexander D. Edwards and Nigel K. H. Slater

Department of Chemical Engineering and Biotechnology, University of Cambridge

New Museums Site, Pembroke Street, Cambridge, CB2 3RA, UK

*Phone: <44> 1223763969

Fax: <44> 1223334796

Email: ade24@cam.ac.uk

**Phone: <44> 1223762953

Fax: <44> 1223334796

Email: nkhs2@cam.ac.uk

\begin{abstract}
We previously demonstrated that a dry, room temperature stable formulation of a live bacterial vaccine was highly susceptible to bile, and suggested that this will lead to significant loss of viability of any live bacterial formulation released into the intestine using an enteric coating or capsule. We found that bile and acid tolerance is very rapidly recovered after rehydration with buffer or water, raising the possibility that rehydration in the absence of bile prior to release into the intestine might solve the problem of bile toxicity to dried cells. We describe here a novel formulation that combines extensively studied bile acid adsorbent resins with the dried bacteria, to temporarily adsorb bile acids and allow rehydration and recovery of bile resistance of bacteria in the intestine before release. Tablets containing the bile acid adsorbent cholestyramine release 250 -fold more live bacteria when dissolved in a bile solution, compared to control tablets without cholestyramine or with a control resin that does not bind bile acids. We propose that a simple enteric coated oral dosage form containing bile acid adsorbent resins will allow improved live bacterial delivery to the intestine via the oral route, a major step towards room temperature stable, easily administered and distributed vaccine pills and other bacterial therapeutics.
\end{abstract}




\section{Introduction}

There are three main applications for oral live bacteria delivery. Firstly, attenuated strains of pathogenic enteric bacteria are attractive candidate vaccines, as oral administration avoids injections. Currently, a number of human clinical trials are in progress testing various strains of attenuated live bacteria for protection against enteric diseases such as Cholera, Enterotoxic E. coli and Typhoid fever [1]. Furthermore, these attenuated bacteria can be genetically modified to carry heterologous antigens from other pathogens or tumours, and be used to provoke immune responses in humans to heterologous antigens after oral administration [2]. Secondly, several enteric bacteria strains are of therapeutic interest in re-colonisation of the intestine after antibiotic treatment [3], in symptomatic relief for sufferers of inflammatory intestinal disease [4], and for modifying gut metabolism (e.g. reduction of cholesterol or reducing gall stone susceptibility [5]). Thirdly, genetically engineered forms of enteric bacteria can be used for delivery of biological therapies (e.g. IL-10 [6]).

An ideal delivery system for oral bacterial immunisation or therapy would have the following features: a simple pill, tablet or capsule, with room temperature stability, would be cheap to manufacture, and would be made from well characterised safe materials to reduce development costs. However, since ingestion of bacterial pathogens represents a major source of infection to humans, the GI tract has several features that act as significant barriers to oral administration of live bacterial vaccines and therapeutics, including stomach acidity and bile acids in the intestine. Therefore, as well as the features mentioned, the delivery system must ensure live bacteria are protected from GI microbicides such as acid and bile. To overcome the extremely low $\mathrm{pH}$ of the stomach, which few bacteria can survive [7], two formulations have been tried, specifically neutralisation with bicarbonate buffers (or similar solutions) and enteric delivery using capsules coated with conventional acid-insoluble enteric polymers. The former technique might be expected to be less effective simply because of the extreme quantity of acid secreted into the stomach, whereas enteric delivery is well established and should deliver live dry bacteria very efficiently past the stomach avoiding any reduced $\mathrm{pH}$. Furthermore, liquid formats of administration present serious safety and logistical problems in third world vaccination programmes; either clean safe water has to be locally sourced to make up buffers, or clean water has to be distributed with the vaccine. In contrast, enteric coated capsules are simple to distribute and administer. Current trials of live bacterial vaccines are conducted using various liquid formulations including carbonate buffer plus additional components such as rice solids to improve palatability (e.g. [8-11]). This format is favoured for early trials since safety and efficacy data can be established without a fully developed formulation as trial participants can be given buffer plus liquid samples from a frozen vaccine cell bank; later trials incorporate bridging studies to demonstrate equivalency of a fully-formulated vaccine (e.g. freeze-dried cells, packaged for distribution) that would eventually become an approved product. Another reason for preferring liquid buffered administration is that large, long-term human field trials showed that administration of three doses of the Typhoid fever vaccine strain Ty21a resuspended in a bicarbonate buffer (78\% protection) gave marginally higher protection to three enteric capsules (62\% protection [12]). This relative failure of the 
enteric capsule delivery suggests loss of live cell viability in the intestine, however enteric bacteria (including Salmonella typhi Ty21a) have robust bile resistance mechanisms and are not thought to be killed by intestinal bile concentrations [13]. In an earlier study [14], we discovered that dried bacteria can have elevated sensitivity to bile, providing an explanation for the poor performance of enteric capsules for live bacterial vaccine delivery- the enteric capsule protects dry cells from stomach acidity, but the cells are then killed by bile on release into the intestine.

In order to protect dried bacteria from bile sensitivity, we hypothesised that a bile acid sequestrant resin (BAR) could be used. 30\% of the cholesterol in humans is found in the form of bile acids in the intestine, and so oral administration of agents that bind bile acids and prevents re-absorption effectively reduces total cholesterol levels. The use of the anion-exchanging resin cholestyramine for reducing cholesterol levels was first demonstrated in 1959 [15], and since then, a wide range of bile acid adsorbant resins have been developed and shown to be safe when taken orally in large doses (e.g. $10 \mathrm{~g}$ per day) [16]. We found that bile- and acid- sensitive dried bacteria rapidly recover resistance after rehydration in buffer. Based on this observation, we wondered if BAR could temporarily protect dry bacteria from a bile solution whilst they recover bile resistance, and therefore tested the sensitivity to bile solutions of dried cells combined in different ways with cholestyramine.

\section{Methods}

\subsection{Reagents and bacteria}

LB (Luria-Bertani) broth, LB agar, ampicillin, M9 salts and all growth medium supplements, phosphate buffered saline (PBS), ox bile, cholestyramine and 400 mesh Dowex 1X2 and Dowex 50WX2, microcrystalline cellulose (MCC, Avicel PH101) were purchased from Sigma (Poole, Dorset, UK). Before use, cholestyramine and other ion exchange resins were washed extensively and neutralised with phosphate buffer and sterilised with 70\% Ethanol before thorough drying. Phosphate buffer used for tablet dissolution was $0.025 \mathrm{M}$ potassium dihydrogen phosphate and $0.025 \mathrm{M}$ di-sodium hydrogen phosphate at pH7.0. Bile solutions were made by dissolving ox bile in either PBS or phosphate dissolution buffer as indicated in the figure legends and sterilised by 0.2 micron filtration. The model live bacterial vaccine strain SLDAPD/pUC18I is a version of Salmonella typhimurium SL3261 modified for stable plasmid maintenance using the ORT-VAC system, and carrying the pUC18I plasmid providing ampicillin resistance [17].

\subsection{Production of room temperature stable dry bacteria}

SLDAPD/pUC18I [14, 17] was grown overnight in M9 medium (M9 salts plus $2.5 \%$ glucose, $1 \mathrm{mM}$ $\mathrm{MgSO}_{4}, 0.1 \mathrm{mM} \mathrm{CaCl}_{2}$, supplemented with amino acids and vitamins or enriched with $1 \% \mathrm{LB}$ broth, as described [14]) and osmotically preconditioned with $300-500 \mathrm{mM} \mathrm{NaCl}$ as indicated [14]. Cells were harvested and resuspended in PBS/40\% trehalose/1.5\% polyvinylpyrrolidone (PVP) followed by drying for $48 \mathrm{~h}$ in a vacuum desiccator, either in $10 \mu \mathrm{l}$ samples in 96 well plates, or in $0.5 \mathrm{ml}$ samples in 24 well plates (forming a glassy foam [18]). For tablet production, several $0.5 \mathrm{ml}$ samples were ground to a 
homogeneous powder in a mortar. In some cases, $5-10 \%$ cholestyramine was added to the drying excipient before adding to cells, as indicated below.

\subsection{Testing bile and acid tolerance of dried bacteria}

To measure the kinetics of bile and acid tolerance after rehydration, replicate $10 \mu 1$ samples of SLDAPD/pUC18I cells were dried in 96 well plates and challenged with buffer, acid or bile by incubation for 60 minutes at $37^{\circ} \mathrm{C}$ either directly in the plates they were dried in $(\mathrm{t}=0)$, or after rehydration in $100 \mu \mathrm{l}$ of LB broth for the indicated times. After challenge, cells were diluted and plated overnight on LB agar to determine live colony forming units (CFU). In all cases bacteria were diluted at least 50 -fold in test media, to ensure no dilution or neutralisation of test buffers, and bile and acid sensitivity was independent of cell density (data not shown and [14]). Live cell counts were corrected for the overall dilution during the assay, and were expressed relative to the original volume of cells dried (relative CFU/ml).

In order to determine if bile acid adsorption by cholestyramine effectively prevents bile toxicity to dried bacteria, a $5 \%$ bile solution was pre-treated with or without $10 \% \mathrm{w} / \mathrm{v}$ cholestyramine for $1 \mathrm{~h}$ at room temperature with mixing. Cholestyramine was removed by centrifugation and 0.2 micron filtration, and total bile acid concentration was measured using the Randox Total Bile Acid Assay (Randox labs, Co. Antrim). The filtered solutions were diluted to the indicated concentrations then added directly to dried SLDAPD/pUC18I cells and incubated for $1 \mathrm{~h}$ at $37^{\circ} \mathrm{C}$, followed by dilution, overnight plating on LB agar for determination of relative $\mathrm{CFU} / \mathrm{ml}$.

To show cholestyramine could protect cells when added directly to dried cells, replicate $10 \mu 1$ samples of SLDAPD/pUC18I cells were dried in $6 \mathrm{ml}$ test tubes. $100 \mathrm{mg}$ of cholestyramine or no resin was added on top of the dry cells, then $2 \mathrm{ml}$ control or bile solutions were added dropwise onto the dry resin. Tubes were incubated for 30 minutes at $37^{\circ} \mathrm{C}$, followed by dilution, plating overnight and colony counting to determine relative $\mathrm{CFU} / \mathrm{ml}$.

The effect of cholestyramine addition into drying excipient was tested as follows:

SLDAPD/pUC18I cells were grown, harvested by centrifugation, and replicate portions were resuspended in drying excipient consisting of PBS/40\% Trehalose/1.5\% PVP either with no addition, with 5\% w/v cholestyramine, or with $10 \% \mathrm{w} / \mathrm{v}$ cholestyramine added. Replicate $10 \mu 1$ samples of these cells were then dried in 96 well plates. Bile resistance was tested by the addition of $200 \mu 1$ samples of various concentrations of bile or control solutions (as indicated in figure legend) and incubation for 30 minutes at $37^{\circ} \mathrm{C}$, followed by serial dilution, plating and incubation overnight on LB agar plates; the resulting colonies were counted and used to quantify relative $\mathrm{CFU} / \mathrm{ml}$.

\subsection{Making and testing compressed matrix tablets}

SLDAPD/pUC18I cells were dried in standard excipient as above, and then ground in a mortar to make a powder. The powdered dried bacteria were mixed in carefully weighed proportions as shown in Table 1.70-90mg samples of the mixed powders were then pressed in a $7 \mathrm{~mm}$ die in a modified $\mathrm{KBr}$ press (Port-A-Press from International Crystal Laboratories, supplied by Crystan Ltd, using 10 newton metres torque applied with a Roebuck torque wrench) to make compressed matrix tablets approximately $1 \mathrm{~mm}$ 
thick. The tablets were then tested for bile resistance as follows: tablets were weighed and individually added to $17 \mathrm{ml}$ portions of phosphate buffer $\pm 1 \%$ ox bile and incubated for 45 minutes at $37^{\circ} \mathrm{C}$. Samples were serially diluted, plated onto LB agar plates, followed by overnight incubation. The resulting colonies were counted to quantify $\mathrm{CFU} / \mathrm{ml}$, and then expressed in terms of the original dried bacteria weight, i.e. in $\mathrm{CFU} / \mathrm{mg}$ of dried bacteria.

\subsection{Imaging anion diffusion into tablets}

Tablets were pressed either with ground sucrose, or sucrose with 50\% cholestyramine, and held between two clear polystyrene plates for imaging with transmitted light from a white light box. To ensure diffusion only occurred from the tablet edges, the plates were coated with a thin film of hydrophobic silicone grease. $10 \mathrm{ml}$ of $1 \mathrm{mg} / \mathrm{ml}$ solution of bromophenol blue in $\mathrm{pH} 7.0$ phosphate buffer was added, and images were captured using a Qicam CCD camera (Qimaging, Surrey, Canada) using Streampix III software (Norpix, Montreal, Canada).

\section{Results}

\subsection{Rapid recovery of bile tolerance after rehydration}

We studied the model live bacterial vaccine strain $S$. typhimurium SLDAPD/pUC18I, previously shown to be bile sensitive when dried in a room temperature stable formulation [14]. Replicate samples were either kept dry or rehydrated with $100 \mu 1 \mathrm{LB}$ broth and kept at room temperature for 1,5 or 20 minutes as indicated. Dry or recovered samples or control cells from rich broth cultures were then tested by incubation for $1 \mathrm{~h}$ diluted extensively in acid or bile solution or control buffer, as indicated, followed by dilution, plating on agar plates, and counting overnight colonies. As expected [14] direct addition of bile solution to dried cells resulted in 37-fold loss of viability compared to buffer (figure $1, t=0$ ). In contrast, even 1 minute after rehydration at room temperature, only 8.7-fold loss was seen, representing a 4-fold increase in viable cell recovery (figure 1). Further recovery was seen after 5-20 minutes (figure 1), and by $1 \mathrm{~h}$ after rehydration, bacteria behaved indistinguishably from control cells from liquid cultures ([14] and data not shown). Similar results were obtained by rehydration in buffer and water, but no recovery was seen if cells were kept on ice during the recovery period (data not shown).

\subsection{The BAR cholestyramine protects dried bacteria from bile toxicity}

Initial tests were conducted to determine if the BAR cholestyramine is suitable for protecting dried bacteria from bile toxicity.

A $5 \% \mathrm{w} / \mathrm{v}$ solution of bile in PBS was pre-treated with $10 \% \mathrm{w} / \mathrm{v}$ of cholestyramine for $1 \mathrm{~h}$, followed by centrifugation and filtration to remove cholestyramine and adsorbed bile acids. Measurement of bile salts using an enzymatic assay demonstrated that the concentration of bile acids was reduced from $130 \mathrm{mM}$ to $0.8 \mathrm{mM}$ by cholestyramine treatment, as expected from the high capacity of cholestyramine for bile acids [19]. The resulting solutions were added at differing dilutions to replicate samples of dried bacteria and incubated for $1 \mathrm{~h}$ at $37^{\circ} \mathrm{C}$, followed by dilution, plating onto LB agar plates, overnight incubation, followed by the quantification of colonies and calculation of relative $\mathrm{CFU} / \mathrm{ml}$. As expected 
untreated bile solutions showed toxicity over a range of concentrations, from 4-fold loss of viable cells at $0.19 \%$, up to 43 -fold loss at $5 \%$ bile. In contrast even at the highest concentration of cholestyraminetreated solution tested (i.e. $5 \%$ bile prior to treatment), no loss of viable cells was detected, confirming that all toxic components of the bile solution were successfully removed by cholestyramine (figure $2 a$ ).

To determine if either cholestyramine or a complex of bile acid bound to cholestyramine is toxic to dried bacteria, dry cholestyramine powder was added on top of a sample of dried bacteria followed by buffer or bile solution addition and incubation for 30 minutes at $37{ }^{\circ} \mathrm{C}$. Cholestyramine alone had no effect on cell recovery in buffer, but when bile solutions were added, cholestyramine completely blocked bile toxicity (figure 2b). This demonstrated that neither cholestyramine nor bile acids complexed to cholestyramine are toxic to dried bacteria.

Finally, we tested if BAR could be combined with the drying excipient, to make a dry bacterial preparation with inherent bile resistance. Drying bacteria with $10 \% \mathrm{w} / \mathrm{v}$ cholestyramine added to the drying excipient resulted in 50-fold more live bacteria when resuspended in a $2 \%$ bile solution than control dried cells (figure 2c). Adding 5\% w/v cholestyramine to the drying excipient gave nearly as much protection (figure $2 \mathrm{c}$ ). This demonstrated the potential of BAR for protecting dried bacteria from bile toxicity.

\subsection{Combining BAR and dried bacteria in a compressed matrix tablet protects bacteria from bile}

Bacteria dried in trehalose can be ground and compressed into matrix tablets [18], and so we tested a simple prototype bacteria pill containing BAR plus dried SLDAPD/pUC18I. We tested tablets containing live dried cells mixed with the fillers sucrose or microcrystalline cellulose (MCC) or MCC mixed with either cholestyramine (a fine powder of Dowex 1X2), a coarser 400 mesh form of Dowex $1 \mathrm{X} 2$ or the control cation exchange resin Dowex 50WX2. Intestinal release was then simulated by dissolution in $1 \%$ bile dissolved in phosphate dissolution buffer, and compared with total live cell release in buffer alone. With control tablets containing dried bacteria diluted in sucrose as a filler, 1228-fold fewer cells were recovered after dissolution in $1 \%$ bile solution compared to dissolution in buffer alone, indicating significant bile toxicity. Similarly, with tablets made using MCC as a filler, 638 -fold fewer cells were recovered after dissolution in a $1 \%$ bile solution compared to buffer alone. In contrast, with tablets containing $33 \%$ cholestyramine or $62 \%$ of the coarser 400 mesh Dowex $1 \mathrm{X} 2$ resin in addition to the dried bacteria and MCC filler, dissolution in bile only gave a 2.5 to 3.1-fold reduction in live cell recovery. This represents an improvement of 208 to 254-fold more live cells with the BAR tablet compared to control tablets. Tablets containing $43 \%$ of 400 mesh Dowex 1X2 resin showed a 26-fold loss in bile, representing a 50-fold improvement over control tablets. Tablets containing the control cation exchange resin Dowex 50WX2, that does not bind bile acids, showed 731-fold loss of cells in bile solution compared to buffer, indicating no protection from bile. Thus, simply compressing BAR with bile-sensitive dried bacteria was sufficient to prevent most bile toxicity.

\subsection{Modelling temporary anion exclusion by BAR in matrix tablets}


In order to visualise how the BAR might prevent bile acid penetration into the hydrating matrix tablets, the dye bromophenol blue (which is anionic and binds cholestyramine at $\mathrm{pH}$ 7) was used to mimic the behaviour of bile acids. Tablets without dried bacteria containing cholestyramine or control tablets made from sucrose alone were imaged during hydration in a $1 \mathrm{mg} / \mathrm{ml}$ bromophenol blue solution, whilst illuminated by a light box providing transmitted light (figure 4; note that this concentration of the bromophenol blue dye appears red under transmitted light conditions). As the tablets are hydrated in the dye solution, the migration of water can be seen into the tablet due to an increase in transmittance of the wet tablet compared to the dry tablet. At the same time, dye penetration can be monitored. When the rate of dye and water penetration was compared visually, a clear difference was seen between control and cholestyramine-containing tablets. By 1 minute after solution addition to the cholestyramine-containing tablet, a clear ring surrounded by a dark blue ring were seen, indicating that water penetrated rapidly but the dye was retarded by adsorption to the cholestyramine. By 6 minutes the entire core of the tablet appeared clear, but the dye had not penetrated significantly, indicating that the tablet can fully hydrate whilst anions are excluded (figure 4). In contrast, with control tablets the dye penetrated fully as the tablet hydrated (figure 4).

\section{Discussion}

Crucial to the development of our novel bile protection formulation was the observation that dried cells rapidly recovered bile tolerance after rehydration (figure 1). This rapid recovery of bile tolerance is similar to that seen in an early studies of bacterial injury caused by freeze-drying [20]. Bacterial injury was defined as the inability of freeze-dried Salmonella anatum to survive plating on nutrient agar supplemented with the bile salt deoxycholine, and may therefore occur through a similar mechanism to the sensitivity of dried cells to bile solutions in the current study. If the same mechanism is responsible, it will be interesting to see if the recovery of bile resistance observed in the current study is dependent on ATP synthesis, as seen for freeze-dried cells [20]. Interestingly, the kinetic for recovery of acid resistance seems slower, suggesting a different mechanism of recovery (figure 1). In the context of oral delivery, however, the rapid recovery of bile resistance suggested that temporary removal of bile acids would be sufficient to protect dry cells from bile after delivery into the intestine using an enteric coating.

We modelled temporary anion exclusion from BAR containing tablets using the dye bromophenol blue. We found that anionic bile acids were adsorbed at the surface of the cholestyramine tablet whilst 'clean' anion-free water diffused rapidly into the core of the tablet (figure 4). The dye penetrated freely into control tablets without cholestyramine. Note that the dye used, bromophenol blue is not intended to model bile acid behaviour precisely, since it is significantly different in size, composition and hydrophobicity. However, the dye has two key features that justify its use. Firstly, it has the same negative charge at $\mathrm{pH} 7$ as bile acids and therefore binds the anion exchange resin cholestyramine. Secondly, it can be simply visualised in real time whereas imaging of bile acid diffusion is not feasible. These images suggest a mechanism for BAR protection of dried bacteria from bile acid toxicity. 
If this proposed mechanism is correct, BAR containing tablets should be able to protect dry bacteria from an excess of bile acids, since initial hydration in the absence of bile acids would allow the dried bacteria to recover their intrinsic bile resistance within the hydrating tablet. Therefore, it is important to calculate the molar quantities of bile acids present in the bile solution used and compare this to the maximal binding capacity of cholestyramine for bile acids. Bile comprises a mix of different bile acids that bind to BAR to differing degrees [19]. The maximal capacity at equilibrium of cholestyramine for bile acids is 2.9-3.8 $\mu$ moles bile acid per mg resin for cholate and deoxycholate, respectively [19]. In the experiments testing bile protection by drying cells with cholestyramine (figure $2 \mathrm{c}$ ), the $10 \mu 1$ sample of bacteria dried with $10 \% \mathrm{w} / \mathrm{v}$ resin contained $1 \mathrm{mg}$ resin with a capacity for 2.9-3.8 $\mu$ moles bile acid. To this, $2 \mathrm{ml}$ of a $2 \%$ bile solution was added, containing a total of $100 \mu$ moles of bile acids. Therefore bile acids were present at a 25 to 34 -fold molar excess over resin in this test. In the experiments testing bile protection conferred by adding cholestyramine to compressed matrix tablets, the tablets tested contained a maximum of $30 \mathrm{mg}$ cholestyramine (calculated for $90 \mathrm{mg}$ tablet with $33 \%$ cholestyramine), with the capacity to bind a maximum of $86-112 \mu$ moles bile acids. They were tested in $17 \mathrm{ml}$ of $1 \%$ bile solution that contained $425 \mu$ moles bile acids. Therefore bile acids were present at a 3.8 to 4.9 -fold molar excess over resin in this test. The protection seen against an excess of bile acids in these experiments indicates that the BAR is not simply sequestering total bile acids in the test sample (as achieved in figure 2a). This supports the proposed model whereby a temporary zone of protection from bile acids is established during hydration of the dry cells, either in the dried cell pellet or in the matrix tablet. The protected rehydration allows the dry bacteria to recover bile tolerance; subsequently, when bacteria are released from the pellet or tablet into the unbound bile acid solution, they are fully tolerant of bile acids.

The importance of bile acid binding for protection is demonstrated by the comparison with the cation exchange resin Dowex 50WX2 that does not bind bile acids. This resin has the same crosslinked polystyrene backbone as Dowex 1X2 but different ion exchange groups, and the 400 mesh preparations of these two resins have the same swelling, water absorption and porosity. Matrix tablets containing this resin showed the same bile sensitivity as control tablets with sucrose or MCC alone, confirming that bile acid binding to the resin is essential to protect the dried cells from bile (figure 3 ).

The current study used bile solutions to accurately determine bile sensitivity in controlled in vitro assays. The concentration of bile acids found in the human intestine typically ranges from $2-10 \mathrm{mM}$ [21], but the concentration in bile secreted from the gall bladder can be as high as $100 \mathrm{mM}$; we previously showed that $3 \mathrm{mM}$ deoxycholine causes significant toxicity to dried vaccine cells, suggesting that intestinal bile acid concentrations are high enough to impact on therapeutic bacterial viability [14]. The bile acid concentrations used in the current study were chosen to reflect a relatively high intestinal bile concentration ( $26 \mathrm{mM}$ total bile acids in a $1 \%$ ox bile solution) in order to stringently test the protection conferred by BAR. However, the exact conditions encountered will depend on a number of factors, including exact position of release by an enteric coating, time of tablet ingestion relative to feeding, nature of food [13]. Therefore, although we have clearly demonstrated protection from bile toxicity using 
BAR, it is difficult to accurately assess how much effect this will have on the live cell dose received after oral administration, and the effects of BAR formulation on bacterial delivery or vaccine efficacy remain to be determined. However, by protecting dry cells from an excess bile acids, the bile concentration encountered should not influence cell viability, eliminating a potential source of variability in live cell delivery.

Further work is needed to optimise formulation of dried bacteria using BAR. Although adding cholestyramine to compressed matrix tablets gave a higher degree of protection compared to adding to the drying excipient (figures $2 \mathrm{c}$ and 3 ), more BAR was used. Increasing the amount of cholestyramine added to drying excipient would require significant modification of the drying protocol. Therefore, we favour the simpler approach of mixing BAR with bacteria post-drying. When added to compressed matrix tablets, the fine powder form of Dowex 1X2 (i.e. cholestyramine) showed similar protection at 33\% as almost double the quantity of a coarser 400 mesh form of the same resin. Furthermore, $43 \%$ of the coarser resin was 5 times less effective at protecting cells than $62 \%$ (figure 3 ). It is likely that the improved protection by cholestyramine reflects either a higher capacity from bile acids or more rapid binding by the fine powder, which has a higher surface area. Thus the quantity of BAR added and the exact form of BAR (e.g. particle size) used has a significant influence on protection from bile. Addition of other BAR such as colestimide with higher bile binding capacity should also be compared [19]. As well as preventing bile acid penetration, tablet composition must be compatible with manufacturing processes and enteric coating and therefore the effects of other additives such as fillers, binders and delayed release excipients must also be determined.

Once an optimal formulation has been established, the ultimate test will be to compare oral bacterial delivery by this formulation with existing formulations such as enteric capsules and buffered liquid formats. The effect of this formulation on live bacterial vaccine function will also need to be determined. In order to do so, a large animal model will be needed for two reasons. Firstly, enteric coated dosages cannot be made small enough for rodents and the mouse intestine has a lower $\mathrm{pH}$ than humans, so enteric polymers will dissolve at a different location. Secondly, the adsorptive separation of bile acids essential to this formulation will be difficult to achieve in a scaled down dose form.

\section{Conclusions}

We present here an initial description of a new bacterial delivery formulation comprising a mixture of dried bacteria and bile acid binding resin, surrounded with a conventional enteric coating. The formulation has the following advantages: an oral tablet represents the simplest possible dosage format; the formulation is cheap and safe since all individual components are already extensively tested in humans; dry bacteria can be stabilised for room temperature storage saving refrigeration costs during distribution; enteric delivery avoids issue of stomach acidity and finally, the BAR incorporated within the enteric coating provides protection from intestinal bile toxicity. We provide here the following evidence to support our formulation: dry bacteria rapidly recover tolerance to bile, if rehydrated prior to bile 
exposure (figure 1); BAR in a tablet can transiently prevent anion (i.e. bile acid) penetration (figure 4); and crucially, either adding the BAR cholestyramine to excipient prior to drying, or formulating matrix tablets with a mixture of cholestyramine plus dried bacteria provides 50 to 250 -fold protection against bile toxicity compared to bacteria tested without cholestyramine (figures 2 and 3).

\section{Acknowledgements:}

Rocky Cranenburgh, Matthew Leckenby, David Thatcher at Cobra Biomanufacturing provided the SLDAPD/pUC18I model vaccine strain and contributed in discussion of the manuscript. Anil Bagha,

Katie Cranleigh-Swash and Chris Morris helped with bile acid measurement and bile sensitivity assays. Nuno Reis helped with tablet imaging. The work was funded by grant project M0024E from the Technology Strategy Board (a business-led executive non-departmental public body, sponsored by the Department for Innovation, Universities and Skills) and the UK Engineering and Physical Sciences Research Council (EPSRC).

\section{References:}

[1] Levine MM. Enteric infections and the vaccines to counter them: future directions. Vaccine 2006 May 1;24(18):3865-73.

[2] Khan S, Chatfield S, Stratford R, Bedwell J, Bentley M, Sulsh S, et al. Ability of SPI2 mutant of $S$. typhi to effectively induce antibody responses to the mucosal antigen enterotoxigenic E. coli heat labile toxin B subunit after oral delivery to humans. Vaccine 2007 May 22;25(21):4175-82.

[3] Bergogne-Berezin E. Treatment and prevention of antibiotic associated diarrhea. Int J Antimicrob Agents 2000 Dec;16(4):521-6.

[4] Bohm SK, Kruis W. Probiotics: do they help to control intestinal inflammation? Ann N Y Acad Sci 2006 Aug;1072:339-50.

[5] Prakash S, Martoni C. Toward a new generation of therapeutics: artificial cell targeted delivery of live cells for therapy. Appl Biochem Biotechnol 2006 Jan;128(1):1-22.

[6] Steidler L, Neirynck S, Huyghebaert N, Snoeck V, Vermeire A, Goddeeris B, et al. Biological containment of genetically modified Lactococcus lactis for intestinal delivery of human interleukin 10. Nat Biotechnol 2003 Jul;21(7):785-9.

[7] Foster JW. Escherichia coli acid resistance: tales of an amateur acidophile. Nat Rev Microbiol 2004 Nov;2(11):898-907.

[8] Kirkpatrick BD, Tenney KM, Larsson CJ, O'Neill JP, Ventrone C, Bentley M, et al. The novel oral typhoid vaccine M01ZH09 is well tolerated and highly immunogenic in 2 vaccine presentations. J Infect Dis 2005 Aug 1;192(3):360-6.

[9] Sack DA, Shimko J, Sack RB, Gomes JG, MacLeod K, O'Sullivan D, et al. Comparison of alternative buffers for use with a new live oral cholera vaccine, Peru-15, in outpatient volunteers. Infect Immun 1997 Jun;65(6):2107-11.

[10] Launay O, Sadorge C, Jolly N, Poirier B, Bechet S, van der Vliet D, et al. Safety and immunogenicity of SC599, an oral live attenuated Shigella dysenteriae type-1 vaccine in healthy volunteers: Results of a Phase 2, randomized, double-blind placebo-controlled trial. Vaccine 2009 Feb 18;27(8):1184-91.

[11] McKenzie R, Darsley M, Thomas N, Randall R, Carpenter C, Forbes E, et al. A doubleblind, placebo-controlled trial to evaluate the efficacy of PTL-003, an attenuated enterotoxigenic E. coli (ETEC) vaccine strain, in protecting against challenge with virulent ETEC. Vaccine 2008 Aug 26;26(36):4731-9. 
[12] Levine MM, Ferreccio C, Abrego P, Martin OS, Ortiz E, Cryz S. Duration of efficacy of Ty21a, attenuated Salmonella typhi live oral vaccine. Vaccine 1999 Oct 1;17 Suppl 2:S22-7.

[13] Begley M, Gahan CG, Hill C. The interaction between bacteria and bile. FEMS Microbiol Rev 2005 Sep;29(4):625-51.

[14] Edwards AD, Slater NK. Formulation of a live bacterial vaccine for stable room temperature storage results in loss of acid, bile and bile salt resistance. Vaccine 2008 Oct 23;26(45):5675-8.

[15] Bergen SS, Jr., Van Itallie TB, Tennent DM, Sebrell WH. Effect of an anion exchange resin on serum cholesterol in man. Proc Soc Exp Biol Med 1959 Oct-Dec;102:676-9.

[16] Charlton-Menys V, Durrington PN. Human cholesterol metabolism and therapeutic molecules. Exp Physiol 2008 Jan;93(1):27-42.

[17] Garmory HS, Leckenby MW, Griffin KF, Elvin SJ, Taylor RR, Hartley MG, et al. Antibiotic-free plasmid stabilization by operator-repressor titration for vaccine delivery by using live Salmonella enterica Serovar typhimurium. Infect Immun 2005 Apr;73(4):2005-11.

[18] Vilchez S, Tunnacliffe A, Manzanera M. Tolerance of plastic-encapsulated Pseudomonas putida KT2440 to chemical stress. Extremophiles 2008 Mar;12(2):297-9.

[19] Honda Y, Nakano M. Studies on adsorption characteristics of bile acids and methotrexate to a new type of anion-exchange resin, colestimide. Chem Pharm Bull (Tokyo) 2000

Jul;48(7):978-81.

[20] Ray B, Jezeski JJ, Busta FF. Repair of injury in freeze-dried Salmonella anatum. Appl Microbiol 1971 Sep;22(3):401-7.

[21] Northfield TC, McColl I. Postprandial concentrations of free and conjugated bile acids down the length of the normal human small intestine. Gut 1973 Jul;14(7):513-8.

Table 1: Composition of compressed matrix tablets

\begin{tabular}{|c|c|c|c|c|c|c|}
\hline Tablet type & $\begin{array}{c}\text { Dried cells in } \\
\text { Trehalose/PVP } \\
\%\end{array}$ & $\begin{array}{c}\text { Sucrose } \\
\%\end{array}$ & $\begin{array}{c}\text { MCC } \\
\%\end{array}$ & $\begin{array}{c}\text { Cholestyramine } \\
\%\end{array}$ & $\begin{array}{c}400 \text { mesh } \\
\text { Dowex 1X2 } \\
\%\end{array}$ & $\begin{array}{c}400 \text { mesh } \\
\text { Dowex 50WX2 } \\
\%\end{array}$ \\
\hline Sucrose control & 9 & 91 & - & - & - & - \\
\hline MCC control & 8 & - & 92 & - & - & - \\
\hline $33 \%$ cholestyramine & 8 & - & 59 & 33 & - & - \\
\hline $62 \%$ Dowex $1 \mathrm{X} 2$ & 6 & - & 32 & - & 62 & - \\
\hline 43\% Dowex $1 \mathrm{X} 2$ & 7 & - & 50 & - & 43 & - \\
\hline 61\% Dowex 50WX2 & 6 & - & 33 & - & - & 61 \\
\hline
\end{tabular}

Numbers indicate $\%$ by weight mixed as dry powder before compression into tablet form of tablets tested in figure 3.

\section{Figure legends}

\section{Figure 1: Rapid recovery of bile resistance after rehydration of dry bacteria}

Replicate dried samples of the Salmonella typhimurium vaccine strain SLDAPD/pUC18I were either directly challenged with buffer, acid or bile solutions $(t=0)$ or rehydrated for the indicated times then diluted extensively into buffer, acid or bile solutions. After $1 \mathrm{~h}$ in test media at $37^{\circ} \mathrm{C}$ cells were diluted, plated on LB agar, incubated overnight and colonies counted to determine viable CFU. Error bars represent standard deviation of replicate counts. A similar kinetic of bile and acid resistance recovery was seen in two independent experiments. 


\section{Figure 2: Protection of dry bacteria from bile toxicity by the BAR cholestyramine}

(a) A 5\% w/v solution of bile (Sigma, Ox-bile) in PBS was mixed with or without $10 \% \mathrm{w} / \mathrm{v}$ of cholestyramine (Dowex 1X2, Sigma, Poole UK) for 1 hour at room temperature, then removed by centrifugation followed by filtration. The resulting solutions were diluted to the indicated concentrations or used neat, and added to replicate samples of dried SLDAPD/pUC18I and cultured for $1 \mathrm{~h}$, followed by dilution, plating on LB agar, incubation overnight, counting colonies and calculation of relative CFU/ml. (b) $10 \mu 1$ dried samples of SLDAPD/pUC18I were dried in $6 \mathrm{ml}$ test tubes. To replicate samples, either nothing or $150 \mathrm{mg}$ of cholestyramine were added on top of the dried cells. Then, $2 \mathrm{ml}$ of a $2 \%$ solution of bile dissolved in PBS or control PBS were added into the tubes, followed by incubation for 30 minutes at $37^{\circ} \mathrm{C}$. After incubation, samples were taken, diluted, plated on LB agar, incubated overnight and colonies were counted, and relative CFU/ml were calculated. (c) SLDAPD/pUC18I were suspended in either control excipient (40\% trehalose, 1.5\% PVP in PBS) or BAR-containing excipient (40\% trehalose, $1.5 \%$ PVP plus 5 or $10 \%$ cholestyramine in PBS) and $10 \mathrm{ul}$ samples were dried in $6 \mathrm{ml}$ test tubes. $2 \mathrm{ml}$ of $2 \%$ or $0.4 \%$ bile solutions in PBS or PBS alone were added and the tubes were incubated for $1 \mathrm{~h}$ at $37^{\circ} \mathrm{C}$, then samples were diluted, plated on LB agar, incubated overnight and colonies counted, and relative $\mathrm{CFU} / \mathrm{ml}$ were calculated. Data shown are representative of two independent experiments.

Figure 3: A prototype human dosage form comprising BAR added to matrix tablets protects dry cells from bile

SLDAPD/pUC18I cells were dried in trehalose, ground, mixed with ground dry sucrose as a filler, or MCC filler alone or with the indicated proportion of resins, then pressed into tablet form (tablet composition listed in table 1). Tablets were weighed and individually added to $17 \mathrm{ml}$ portions of $\mathrm{pH} 7$ phosphate buffer with or without $1 \%$ ox bile, and incubated for 45 minutes at $37^{\circ} \mathrm{C}$. Samples were taken, diluted, plated on LB agar, incubated overnight and colonies counted to determine viable CFU. The bacterial count recovered was then expressed in terms of the weight of original dried bacteria, and each bar represents a single tablet, with the error bar representing standard deviation of between 4 to 8 replicate counts for the tablet. Similar protection from bile toxicity was seen in 5 independent experiments, and equivalent cell recovery was seen after 30 minutes, 45 minutes or 1 hour incubation with dissolution solutions.

\section{Figure 4: Modelling anion penetration into BAR matrix tablets}

Tablets were pressed either with ground sucrose, or sucrose with $50 \%$ cholestyramine, and held between two clear polystyrene plates for imaging. The tablets were illuminated with white transmitted light and imaged with a CCD camera, whilst a $1 \mathrm{mg} / \mathrm{ml}$ solution of bromophenol blue in $\mathrm{pH} 7$ phosphate buffer was added. Images shown represent the indicated time points after dye addition, and illustrate hydration of the tablets indicated by increased light transmittance, as well as dye penetration indicated by red/blue colour. Images are representative of at least 5 replicate tablets. 